\title{
Claudia Borzi
}

\section{Consideración del uso de la cláusula ditransitiva en el discurso}

\section{Introducción}

El presente trabajo, en el marco de un enfoque cognitivo prototípico en la línea de Lakoff 1987 y de Langacker 1991, reconsidera las explicaciones que ofrece la bibliografía al definir y caracterizar la cláusula ditransitiva (CD) sobre distintas lenguas. Encuentra que se la caracteriza explícita o implícitamente a partir del mismo perfilamiento de la interrelación y con los mismos criterios con los que se definió la cláusula transitiva, es decir, haciendo hincapié en el traslado de energía de un origen a un destino, en una conceptualización lineal y sucesiva y ordenada según la secuencia agente $>$ paciente $>$ dativo/receptor/poseedor/experimentante. ${ }^{1}$ La presencia de más participantes en la $\mathrm{CD}$, da lugar a la búsqueda de preeminencia de alguno de ellos por sobre los restantes. Así los autores destacan, alternativamente, la importancia del dativo, del agente o de ambos, minimizando el peso del paciente. Otros autores se interesan por la distribución de la información y la manifestación de cada uno de los participantes en la cláusula. En ese marco, proponemos el análisis del comportamiento de los participantes de CDs con dar recolectadas dentro de una serie de narraciones cortas. Se atiende a la continuidad de los designados de los participantes según la distribución de la información, su manifestación, la relación entre ellos y su conceptualización. Se compara luego el comportamiento del paciente con el que muestra este participante en cláusulas transitivas. Se sostiene un funcionamiento discursivo diferente para uno y para otro tipo de cláusulas que lleva a proponer una representación de la $\mathrm{CD}$ con tres vértices, es decir una representación diferente de la que sugiere la cláusula transitiva que es lineal y sucesiva.

1 Se opta por estas denominaciones omitiendo el benefactivo, por sugerencia de uno de los dictaminadores, en tanto estas retoman la caracterización morfológica y la terminología de Langacker (1991, §7.3.3) atendiendo a la diferenciación entre dativo y benefactivo de Maldonado (2000, 111-129) entre construcciones con $a$ y con para.

Claudia Borzi, Consejo Nacional de Investigaciones Científicas y Técnicas y Universidad de Buenos Aires, Ciudad Autónoma de Buenos Aires, Argentina

๖ Open Access. ( 2019 Claudia Borzi, published by De Gruyter. (cc)BY-NC-ND This work is licensed under a Creative Commons Attribution-NonCommercial-NoDerivatives 4.0 International License.

https://doi.org/10.1515/9783110605679-010 


\section{La concepción de la ditransitividad}

Como claramente resume Cano Aguilar para los análisis del español, desde los inicios de la gramática, la transitividad (de transire) plantó el germen de todas las líneas que luego se siguieron en su definición: que un miembro no se basta a sí mismo (incompletitud semántica) y necesita referirse a otro (definición del objeto directo); que plantea idea de paso o tránsito y se opone a lo inmanente (1987, 15-16). Estos conceptos se reformularon luego hasta nuestros días. La Gramática de la Academia de 1931 abre la línea que define el verbo transitivo a partir del lugar en que recae la acción y por el paso a pasiva, definiendo el verbo intransitivo por la negativa. Con idéntico punto de partida, Gili Gaya sale del verbo a la construcción e introduce implícitamente la problemática ditransitiva en la competencia entre participantes, destacando el paciente en la estrecha relación que entabla con el verbo con el que como unidad reciben un objeto indirecto (1967, 209, citado por Cano Aguilar). Y cuando Lenz (1935), dice que en "Juan da una bofetada al niño", el niño no sufre "indirectamente" la acción, preludia la competencia entre paciente y dativo. La oposición inmanencia/transitividad está detrás de la noción de rección, entendida como una cohesión de tipo medio entre verbo y sustantivo (acusativo) que se opone a la inherencia de las oraciones atributivas (Cano Aguilar 1987, 22-23). A partir de estos antecedentes, Campos (1999, 1529) retoma la definición tradicional de "transitividad" como propiedad del verbo que rige sintáctica y semánticamente un complemento directo. Sin embargo, en la discusión previa (1999, §24.1), compatibiliza la rección sintáctica del objeto directo con una definición semántica que abre dos líneas: los dos participantes (sujeto experimentante o agente -los menciona en este orden-) y objeto paciente o tema) y la incompletitud del verbo. Campos sostiene que la intransitividad es una predicación completa que se opone a las incompletas (transitivas y copulativas). Aunque sin aludir a un proceso derivativo, ve la intransitividad como previa (en algún sentido) a la transitividad. Esta última idea es la que lo ubica cerca de los autores que contemplan la complejización de la cláusula a partir de la polisemia de los roles semánticos y su división desde un macro-rol sujeto en la intransitividad que se divide en agente y paciente en el evento transitivo y cuyo paciente vuelve a dividirse en el ditransitivo, como resumen Malchukov y Narrog (2008, 518-524). Retomando de alguna manera esas dos líneas abiertas por Campos, los dos participantes y la incompletitud del verbo, la Nueva gramática de la lengua española de la Academia (Real Academia Española 2009, §§34.1a y d) parte de la transitividad (la trata antes que la intransitividad), pero también 
se refiere a la incompletitud de los verbos transitivos ${ }^{2}$ para concluir que es una categoría que describe verbos que exigen argumento objeto directo. Como no trabaja con un modelo que admita gradaciones, y no contempla la prototipicalidad, el hecho de que haya oraciones con objetos más o menos afectados la lleva a tomar distancia de las definiciones semánticas que contemplan la afectación del objeto o el desplazamiento de energía y que no pueden aplicarse a todos los casos $(2009, \S 34.1$ e). No propone otra definición semántica y fluctúa entre considerar que es dependiente del significado del verbo (2009, §34.1h) o del "uso" (2009, §34.1j), sin delimitar este concepto. Tampoco excede los límites oracionales en su caracterización. Desde un marco discursivo, $\mathrm{Du}$ Bois (2003) adhiere explícitamente a la complejización del verbo como proceso desde la intransitividad hacia la ditransitividad. Así dice "In this respect one can interpret the development from intransitive to transitive to ditransitive verbs as a gradual growth in complexity" $(2003,42)$

También partiendo del discurso. y clasificando cláusulas (no verbos), podemos mencionar a Langacker, quien coincide con las gramáticas tradicionales españolas, que clasificando verbos (no cláusulas) también parten de la transitividad, aunque (Langacker 1991, §7.1.1), a diferencia de estas y de otros autores, explica esta prioridad por significancia cognitiva. Se basa en preferencias básicas de los hablantes, tales como el todo a la parte, lo físico a lo abstracto, las entidades perceptibles y contrastantes, la fuente de la energía, el cambio perceptible. Estas preferencias fundamentan distintos grados de prototipicidad en la conceptualización de eventos y, consecuentemente, de cláusulas. Se centra así en la cláusula transitiva prototípica (CTP), la caracteriza y a partir de esta presenta otras cláusulas básicas, las intransitivas y las de estado asociadas a distintos arquetipos conceptuales (1991, 302-3).

Yendo ahora hacia la ditransitividad, y como antesala del resumen de las propuestas de los autores consultados, digamos que estos coinciden en destacar su mayor complejidad estructural. Comparativamente menos estudiada, se la presenta como dependiente de la transitividad. ${ }^{3}$ Los acercamientos más gramaticales, además de estudiar el comportamiento gramatical de los argumentos, atienden al comportamiento del clítico dativo. Otros proponen una explicación cognitiva y la conectan con las preferencias del enunciador y con el

\footnotetext{
2 Así dice, con subrayados nuestros: "Los verbos tienden a ser transitivos o intransitivos en función de su propio significado. [. . . unos verbos requieren como complemento un argumento que complete la significación [. . . mientras que [. . . otros no” (Real Academia Española 2009, §34.1h). 3 No encontramos un autor que se haya centrado en la ditransitividad para explicar los otros esquemas, algo evidentemente posible para enfoques desligados de la cuantificación y del uso en el discurso.
} 
uso en el discurso. Los trabajos sobre el inglés diferencian las construcciones de dativo externo e interno. El español cuenta con una sola construcción ditransitiva con evidente paralelismo formal con el dativo externo del inglés. No es así de evidente la distribución de valores semánticos. Por esta razón se incluyen también las descripciones del dativo interno.

Wierzbicka (1988) compara los casos de dativo interno y externo del inglés, y en su descripción contempla la transferencia de un objeto desde un agente a un dativo. Para el dativo interno ${ }^{4}$ hace hincapié en la competencia entre los participantes paciente y dativo, que resuelve diciendo que la intención del enunciador es destacar a uno de ellos: el dativo. Sostiene que tanto paciente como dativo, están afectados, pero que para el enunciador es más importante o interesante lo que le ocurre al dativo, el efecto de la acción sobre este. ${ }^{5} \mathrm{Y}$ esto es así porque el paciente es típicamente no humano y en la CD no sufre un cambio drástico, mientras que, por un lado, el dativo (como el agente) es típicamente humano (lo que los eleva en la escala de interés del enunciador), y por otro, el agente busca que le ocurra algo al dativo, y que ese algo lo favorezca. Para la CD con dativo externo la autora contempla solamente una de las expectativas, que el agente hace algo al paciente porque el agente busca que le pase algo al dativo.

Langacker $(1991,310)$ en una visión cercana a Wierzbicka, parte de su concepción de la CTP y de la transferencia de un objeto desde el agente, como fuente de energía, hacia el receptor, destino final. Entre los participantes, destaca la prominencia del agente y del receptor, que puede verse como poseedor o experimentante (según cuál sea el verbo de la cláusula), en detrimento del paciente. En palabras de Langacker, en casos como The bank transferred the deed to the buyer, ${ }^{6}$ "The sentences portray the object as moving abstractly into the dominion of the recipient, and the subject is construed as supplying the energy that induces the transfer". Entendemos que Langacker interpreta tanto las $\mathrm{CD}$ con dativo externo como las de dativo interno en el marco del modelo cognitivo idealizado de cadena de acción. En relación con la prominencia de los participantes, destaca la de agente y receptor, en tanto ambos son participantes que se espera sean activos. La CD con verbo de transferencia se inscribe así en el modelo de cadena de acción. Respecto de la preferencia por el dativo frente al paciente, ofrece diferentes razones: su rol de destino final de la cadena; ser el otro participante iniciador en tanto elabora la recepción, y resultar,

4 Compara el dativo interno en Jim threw Betty an Apple con el externo en Jim threw an apple to Betty.

5 Dice Wierzbicka: "the speaker's attention is focused primarily on the effect of the action on the target person" $(1988,362)$.

6 Ejemplo (25a) del autor. 
finalmente, el poseedor. Esto lo diferencia de Wierzbicka, para quien la competencia se da en especial entre paciente y dativo.

Malchukov, Haspelmath y Comrie (2010), en el marco del proyecto Ditransitive Constructions in the World's Languages, focalizan también el dativo, y su conceptualización como entidad animada y destino final de la transferencia. Sostienen que los ditransitivos son verbos de transferencia física o mental (como "to show" o "to tell") en los que un agente causa que un objeto pase a posesión de un receptor animado (ejemplifican con "to give”), que resultará el poseedor, merced a la ductilidad y polifuncionalidad que muestra el dativo en las lenguas.

Palancar (1999), quien explícitamente parte de Langacker, analiza eventos o acciones de golpear en español y engloba así las CD. Sostiene que tanto "dar” como "pegar" en el sentido de "adherir", han derivado diacrónicamente en "golpear". También este autor se centra en la transferencia, pero incorpora un aspecto no priorizado por otros: focaliza la "direccionalidad espacial" de dicha transferencia, que implica el movimiento de un objeto hacia alguien $(1999,70),{ }^{7}$ y si bien enfatiza la afectación del receptor $(1999,66)$, de alguna manera destaca también el paciente (“a kick”) ${ }^{8}$ al verlo como foco pragmático (Cf. 1999, §4).

Siguiendo la discusión sobre el español, Demonte, por ejemplo (2002, §4), ${ }^{9}$ que agrupa los predicados ditransitivos con los transitivos, sostiene que la conceptualización está centrada en el agente y, consecuentemente, que dependen de un (hiper)predicado "causa" o "hace". Podemos pensar que también Campos (1999, §24.3) se centra en el sujeto (agente), dado que sigue a Demonte, ve la intransitividad como primaria, no reconoce los ditransitivos como categoría diferente $y$, al tratar la selección sintáctica del complemento indirecto, caracteriza los transitivos con un agente/causa. En un apartado, clasifica “dar" como verbo de transferencia (1999, Nota 63) de clítico obligatorio (1999, §24.3.3), con un objeto indirecto generalmente animado, que semánticamente debemos clasificar como dativo de recepción o destino (1999, §24.3.2). En otro lugar, cuando analiza el complemento directo (1999, §24.2.2.E) Campos analiza "dar" como verbo transitivo de posesión, de objeto afectado, efectuado

7 Dice el autor: "la construcción dativa destaca la direccionalidad espacial de la transferencia que expresa” (Palancar 1999, 70, mi traducción).

8 Está interpretando la acción de golpear como la transferencia de una patada hacia el receptor que manifestará "bene- or malefactive nuances" como resultado de dicha transferencia (Palancar 1999, 64).

9 Desde un enfoque lexicalista sostiene que hay predicados básicos: causar, llegar a un estado/lugar, mover(se), estar-ndo y ser/estar. Define "transitividad" e "intransitividad" como epifenómenos de una red de propiedades abstractas de las que sale la sintaxis. 
o desplazado. En línea con los anteriores, la Real Academia Española (2009) clasifica verbos que denotan transferencia (que incluyen los de comunicación, demanda, intercambio); asignación y afección. Discute los diversos significados que se pueden asignar al participante dativo, aunque no evalúa en la descripción ni la relación entre los participantes, ni su manifestación lingüística en la oración (Real Academia Española 2009, §35.5).

En resumen, al definir la ditransitividad, los autores enfatizaron distintos aspectos de la conceptualización de la cláusula. La transferencia es rectora en Wierzbicka (1988), Langacker (1991, 310) y Palancar (1999) por ejemplo. Wierzbicka destaca que paciente y dativo están afectados tanto en el dativo interno como en el externo del inglés, pero en el dativo interno es más importante o interesante para el enunciador lo que le ocurre al dativo $(1988,362)$, contrastado con el paciente, porque el paciente no sufre cambio drástico. No enuncia para el dativo externo esta preferencia del enunciador. Para Langacker, en cláusulas con verbos de transferencia, el objeto directo tiene un rol esencialmente pasivo, mientras que el dativo es activo-iniciador en distintos aspectos como lo es el agente (1991, 328). Por su parte, Demonte (2002, §4), para el español, pone en el centro la agentividad del agente.

Se advierte así que los análisis centrados en verbos y en cláusulas ofrecen explicaciones que atienden al funcionamiento interno de los participantes en la cláusula y a sus conceptualizaciones, buscando de alguna manera una jerarquización entre los implicados en esta relación de tres. La conceptualización de la CD se mantiene en una visión horizontal que, especialmente para el dativo externo, la construcción más paralela a la CDdar en español, podemos interpretar en el marco de los planteos de Langacker respecto del modelo cognitivo idealizado de cadena de acción, que ordena los participantes en una transferencia sucesiva de energía desde el origen (head) hasta el destino (tail): del agente, al paciente y luego al dativo, siguiendo la representación del autor en la Figura 1 (Cf. Langacker 1991, Figura 7.1). ${ }^{10}$

Si los autores anteriores no contemplaron el funcionamiento de la CD en la continuidad del discurso, sí lo hizo Du Bois (2003). Este autor se centra en cómo se manifiesta la distribución de la información. Explica la CD en el marco

10 Langacker dice "A useful construct for describing many aspects of clause structure is the notion of an action chain, [...] An action chain arises when one object makes forceful contact with another, resulting in a transfer of energy; this second object is thereby driven into contact with a third, again resulting in the transmission of energy; and so on indefinitely, until the energy is exhausted or no further contact is made. [. . . Naturally, the simplest non-degenerate action chain is one in which the head and tail interact without intermediaries, so that there are only two participating objects" (1991, 283-285). 


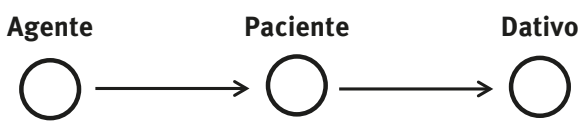

Figura 1: Interpretación de la CD a partir del modelo cognitivo idealizado de cadena de acción.

de las elecciones que enumera al enunciar la estructura argumental preferida; asimila el comportamiento de la CD al de la CT en tanto ambas presentan solamente una frase nominal, siendo esta la que manifiesta el paciente, y no el agente (ni el dativo en la CD), y estando justificada porque el objeto paciente es el que puede acomodar más naturalmente referentes nuevos (Du Bois 2003, 36-37). ${ }^{11}$ La observación de que los dativos son típicamente codificados con formas tenues (clíticos) y denotan tópicos continuos ha sido también sostenida, a partir de datos de corpus, por varios otros autores tales como Company Company (2006) y Belloro (2009, 2015), por ejemplo.

Con el objetivo de seguir describiendo la CD, en especial la CDdar, y teniendo presentes los planteos reseñados, podemos pensar las siguientes preguntas: ¿Se elige el paciente para el único nominal de sustantivo solamente por la calidad de la información? ¿La CDdar se diferencia de la CT solamente en que tiene un participante más? ¿La CDdar se comporta discursivamente igual que la CT?

\section{Metodología}

Los ejemplos analizados en este trabajo provienen de 45 relatos cortos (Galeano 2015) en los que aparece al menos una vez una cláusula con “dar”. Para la constitución de la muestra se rastrearon las formas finitas y no finitas de "dar". Se incluyeron solamente los usos cuyos tres participantes quedaban mencionados explícitamente. ${ }^{12}$ Se omitieron los casos

11 Sostiene Du Bois "If we look at ditransitives, with their three structural opportunities for lexical argument realization, we nevertheless find that the same quantity and role constraints are observed as for transitives [...]. Even with three-place verb like send or pass, still only one of the three arguments is typically realized lexically [...]. Again, as with transitives, lexical mentions are avoided in A, while they freely appear in $\mathrm{O}$. As for the third argument position, the indirect object (I) is typically realized with reduced form, as illustrated in the above examples."

12 Se omitieron por ejemplo casos como los siguientes: "Los indios quillacingas no tienen nada para dar” (Galeano 2015, 49); “Dadas las diez de la noche” (Galeano 2015,140). 
donde "dar" forma fraseologismo; construcción pronominal o recibe complemento preposicional. ${ }^{13}$ Se reunieron 49 ejemplos.

Teniendo en mente las preguntas planteadas, se analizó el estatus informativo de los participantes de la CDdar y de los participantes de CTs y las cadenas de sus designados a izquierda y a derecha de dicha CDdar, conforme la metodología que se explica seguidamente.

Se consideraron cláusulas no solamente aquellas que mostraban verbo conjugado, sino también las de verboide, las relativas adjetivas ${ }^{14}$ y las de discurso directo. ${ }^{15}$ Para la medición de la persistencia se midió la cláusula inmediata a la derecha de la CDdar y de la CT. Se tuvo en cuenta además la vigencia del designado, tanto hacia la izquierda de la cláusula bajo análisis como hacia la derecha en el texto. Los criterios para esta identificación fueron los mismos.

Se analizó primero la distribución de la información en cada CDdar, contemplando la continuidad tópica de cada participante. Para la identificación de la información conocida/nueva se siguieron planteos de la Escuela de Praga (Firbas 1992 y 1994, Hájičovà 1973 y Sgall 1975). Conforme la metodología aplicada en trabajos anteriores (Borzi 2015), como información conocida incluimos la información que pertenece al universo del discurso a. por haber sido mencionada explícitamente dentro del contexto previo por identidad léxica (o repetición); b. por haber sido mencionada por semejanza léxica de sinonimia, hiperonimia, hiponimia, antonimia, contigüidad (de relación parte/todo, por inclusión); c. por conocimiento de mundo; $d$. por conocimiento enciclopédico; e. por ser información que se puede inferir del contexto lingüístico previo (gracias a procesos deductivos o a pistas que parten de un mismo marco o "script"); o f. por ser información evidente, de inmediata interpretación, por estar presente en la situación de enunciación. Se identificó luego la manifestación lingüística de cada uno de los participantes contemplando si aparecía codificado en un nominal de sustantivo; manifestado por pronombre personal variable (nominativo, dativo, paciente en cada caso); por la desinencia verbal (en el caso del agente); por pronombre variable posesivo o por la flexión en género y/o número de adjetivos o participios. Dichos recursos para mantener la continuidad tópica, la persistencia en la cláusula siguiente (Givón 1983) y la vigencia de los participantes en adelante en el

13 Los siguientes ejemplos de la obra son representativos de los casos dejados de lado en la muestra analizada: “(La planta) dio frutos” (Galeano 2015, 36); "Dio fe” (Galeano 2015, 116); “dio a luz" (Galeano 2015, 64); “le dio de comer (Galeano 2015, 77); "Le diera de mamar” (Galeano 2015, 79).

14 A diferencia de lo que hace Bentivoglio (1983, 259-60).

15 En el siguiente ejemplo se contabilizaron 4 cláusulas: "Vanbel estalla, se arranca la peluca, vocifera: -iQuemen a ese negro!” (Texto 34. 1700, Isla de Santo Tomás, El que hace hablar a las cosas). 
texto, se los consideró de forma jerárquica en cuanto a su mayor/menor poder de evocación de los designados, partiendo de la escala de Bentivoglio (1983, 255-311) para el español. Se asoció información y constitución interna del nominal (básicamente: información nueva nominal de sustantivo con distinto grado de determinación y de distinta complejidad versus información conocida con nominal determinado > pronombre > desinencia verbal) y se reconstruyó la escala según los casos presentes en cada relato.

En el análisis de la continuidad, al identificar las cadenas tópicas de los designados y sus manifestaciones lingüísticas, si bien se tomaron como puntos de partida las propuestas de Givón (1983, 5-41) y de Langacker (1991, §7.1.2) en particular, es una propia interpretación la que tratamos de materializar en el análisis, interpretando la idea de los distintos perfilamientos que el enunciador construye para cada designado. A partir de nuestra interpretación, se consideró que el designado vuelve a conceptualizarse al convivir con otros designados y con distintas interrelaciones verbales, en cada cláusula y en cada párrafo temático o fragmento discursivo. Esto se ejemplifica en el análisis de los Textos 1 y 2 (Figuras 2 y 3). Es así que, cuando se establecieron las cadenas de continuidad, se consideró la identidad de los designados discursivos, independientemente de las descripciones usadas para denotarlos. Se trató de mostrar al mantener diferentes números y distinto tipo de letra en las Figuras 2 y 3, que en la descripción de la continuidad se incluyeron sucesivamente nominales de distinta complejidad, formas pronominales (incluidas las posesivas que modifican a un núcleo de designado diferente), desinencias verbales, así como marcas de concordancia en género y en número.

En cada texto, las cadenas de continuidad de los participantes de la CDdar se analizaron de la siguiente manera ${ }^{16}: 1$. La cláusula con “dar” bajo análisis (CDdar) se consideró el punto de partida hacia su izquierda (para determinar la continuidad tópica) y 1 cláusula hacia su derecha (la persistencia). Se identificaron en dicha CDdar los designados ${ }^{17}$ de los participantes agente, dativo y paciente. Se consignó la manifestación lingüística de cada participante en la CDdar, según la siguiente diferenciación. El agente con negrita + mayúsculas + subrayado. El designado del agente de la CDdar se identifica con número 1 volado. El dativo en negrita + mayúsculas. El designado del dativo de la CDdar con número 2 volado. El paciente en mayúsculas. El designado del paciente de la CDdar con número 3 volado. En las CTs se atendió solamente a la persistencia en 1 cláusula a partir de

16 Se omite el título en el establecimiento de las cadenas.

17 Elegimos decir "designado" en lugar de "referente" porque aludimos a construcciones discursivas. 
la cláusula donde ingresa el participante paciente ( $1^{\text {era }}$ mención) en función objeto directo señalizado en negrita en la CT y su designado en la persistencia en 1 cláusula en negrita + cursiva (sin numeración volada).

Se ejemplifica el procedimiento sobre el relato "1560. Huexotzingo. La Recompensa", Texto 1, que se transcribe en la Figura 2 y sobre el Texto 2, más adelante en la Figura 3.

1. Los jefes indigenas de Huexotzingo ${ }^{1}$ llevan ${ }^{1}$, ahora, los nombres de sus $^{1}$ nuevos señores ${ }^{2} . \mathrm{Se}^{1}$ llaman $^{1}$ Felipe de Mendoza, Hernando de Meneses, Miguel de Alvarado, Diego de Chaves o Mateo de la Corona. Pero escriben ${ }^{1}$ en $\mathrm{su}^{1}$ lengua, en lengua náhuatl, y en ella dirigen ${ }^{1}$ una larga carta al rey de España ${ }^{2}$ Infortunados ${ }^{1} \operatorname{somos}^{1}$, pobres vasallos vuestros de Huexotzingo ${ }^{1}$...

2. Explican ${ }^{1}$ a Felipe $I^{2}$ que no pueden ${ }^{1}$ llegar hasta él ${ }^{2}$ de otra manera porque no tienen ${ }^{1}$ con qué pagarse ${ }^{1}$ el viaje, y por carta cuentan ${ }^{1} \operatorname{su}^{1}$ historia y formulan ${ }^{1} \operatorname{su}^{1}$ demanda. ¿Cómo hablaremos? ¿Quién hablará por nosotros ${ }^{1}$ ? Infortunados ${ }^{1}$ somos $^{1}$.

3. Ellos ${ }^{1}$ no han ${ }^{1}$ dado nunca guerra a los españoles ${ }^{2}$. Veinte leguas caminaron ${ }^{1}$ hacia Hernán Cortés ${ }^{2}$ y $l_{0}^{2}$ abrazaron $^{1}, \operatorname{lo}^{2}$ alimentaron ${ }^{1}$ y $10^{2}$ sirvieron $^{1}$ y cargaron ${ }^{1}$ a sus ${ }^{2}$ soldados enfermos. $L E^{2}$ diero $\underline{\mathbf{N}}^{1}$ HOMBRES Y ARMAS Y LA MADERA PARA CONSTRUIR LOS BERGANTINES QUE ASALTARON TENOCHTITLÁN ${ }^{3}$. Caída la capital de los aztecas, los de Huexotzingo ${ }^{1}$ pelearon ${ }^{1}$ luego junto a Cortés $^{2}$ en la conquista de Michoacán, Jalisco, Colhuacan, Pánuco, Oaxaca, Tehuantepec y Guatemala. Muchos ${ }^{1}$ murieron ${ }^{1}$. Y después, cuando nos $^{1}$ dijeron $^{2}$ que rompiéramos ${ }^{1}$ las piedras $y$ quemáramos ${ }^{1}$ las maderas que adorábamos ${ }^{1}$, lo hicimos ${ }^{1}, y$ destruimos $^{1}$ nuestros templos... Todo lo que mandaron ${ }^{2}$, obedecimos ${ }^{1}$.

4. Huexotzingo ${ }^{1}$ era un reino independiente ${ }^{1}$ cuando los españoles ${ }^{2}$ llegaron $^{2}$. Ellos ${ }^{1}$ nunca habian 1 pagado tributo a los aztecas. Nuestros. padres, abuelos $y$ antepasados ${ }^{1}$ no conocian ${ }^{1}$ el tributo $y$ a nadie lo pagaban ${ }^{1}$.

5. Ahora, en cambio, los españoles ${ }^{2}$ exigen $^{2}$ tan altos tributos en dinero y en maiz que declaramos ${ }^{1}$ ante $\mathrm{Su}$ Majestad ${ }^{2}$ que no pasará mucho tiempo antes de que nuestra ciudad de Huexotzingo ${ }^{\mathrm{I}}$ desaparezca $^{1}$ y muera.

Figura 2: Texto 1: “1560. Huexotzingo. La Recompensa”.

Se desarrolla seguidamente un análisis general del Texto 1 pensando en que, como seguramente hay otras interpretaciones posibles del relato, la propuesta de reconceptualización de participantes en la CDdar descansa en nuestra interpretación.

Al comienzo del relato el narrador introduce y describe el contraste de la vida de "los jefes indígenas de Huexotzingo" tras la conquista, antes jefes ahora vasallos. El conflicto entre indígenas y españoles (los dos designados en competencia en todo el relato), se encuentra en la escritura de una carta con demandas al rey de España, un objeto también con dos caras. Es así que, con la 
1. Por los alrededores del alcázar de Toledo, el domador pasea al tigre $^{2} q u e^{2}$ el rey ha recibido desde el Nuevo Mundo. El domador, lombardo de ancha risa y bigotes en punta, $\underline{l o}^{2}$ lleva de la cuerda, como a un perrito, y el jaguar ${ }^{2}$ se desliza ${ }^{2}$ por la grava con pasos de algodón.

2. A Gonzalo Fernández de Oviedo se le hiela la sangre. Desde lejos, grita al guardián que no se fie, que no dé conversación a bestia $^{2}$ fiera, que tales animales ${ }^{2}$ no son $^{2}$ para entre gentes.

3. El domador se ríe, suelta el jaguar ${ }^{2}$ y $\underline{l}^{2}$ acaricia $\underline{e l ~ l o m o^{2}}$. Oviedo alcanza a escuchar el profundo ronroneo ${ }^{2}$. Bien sabe él que ese gruñido entre dientes ${ }^{2}$ significa rezo al demonio ${ }^{2}$ y amenaza $^{2}$. Un día no lejano, este confiado domador caerá en la emboscada. Tenderá la mano para rascar al tigre $^{2}$ y de un veloz zarpazo ${ }^{2}$ será engullido. "¿Creerá este infeliz que DIOS ${ }^{1}$ $\underline{\mathrm{A}}^{1}$ dado $\boldsymbol{A L} \boldsymbol{J A G U \boldsymbol { A } \boldsymbol { R } ^ { 2 } \text { GARRAS Y DIENTES }}{ }^{3}$ para que un domador $\mathrm{le}^{2}$ sirva de comer a horas fijas?" Nunca ninguno de su linaje ${ }^{2}$ comió $^{2}$ llamado $^{2}$ con campana a la mesa, ni tuvo ${ }^{2}$ otra regla sino devorar. Oviedo mira al sonriente lombardo y ve un montoncito de carne picada entre cuatro cirios.

4. — ¡Cortadle $^{2}$ las uñas ${ }^{3} !$ - aconseja, yéndose- ¡ ¡Sacadle ${ }^{2}$ las uñas $^{3}$ de raíz, y todos los dientes y colmillos ${ }^{3}$ !

Figura 3: Texto 2: “1526 - Toledo - El tigre americano".

voz distanciada del narrador, los jefes "llevan, se llaman, escriben en su propia lengua, dirigen”. Surge inmediatamente una segunda voz, la de los indígenas, que en primera persona plural (Infortunados somos) aparece en discurso directo en el texto de la carta. Ambas voces se diferencian también en el tipo de letra (redonda versus cursiva respectivamente). Se marcan los dos perfilamientos, jefes/vasallos, de cada una de las dos voces con diferentes personas gramaticales. Los indígenas se presentan como "vasallos vuestros [de Felipe II, Rey de España] de Huexotzingo". El narrador mantiene la $3^{\text {era }}$ persona del plural en posesivos y verbos (destacado seguidamente con negrita: "explican, no pueden, no tienen, pagarse, cuentan, su, formulan su demanda") y usa un presente histórico que acerca la narración.

En los párrafos siguientes la voz del narrador y la de los indígenas se mantienen a veces separadas y otras, adoptan la misma orientación (Voloshinov 1976). En el inicio del $3^{\text {er }}$ párrafo, solamente el pronombre "ellos" explicita al narrador que coincide en la orientación interpretativa de los hechos con la voz de los jefes "no han dado nunca guerra" alternando el pretérito perfecto y el simple, describiendo puntualmente las acciones: "abrazaron” a Cortés, dicen. Pero al finalizar el párrafo, se profundiza la modificación analítica de la textura, en términos de Voloshinov (1976, 143-194), y reaparece el discurso en $1^{\text {ra }}$ persona (cuando nos dijeron que rompiéramos ... ). El $4^{\text {to }}$ y el $5^{\text {to }}$ párrafo, con 
un juego semejante, se oponen temporalmente en un antes y un ahora que presagia un oscuro futuro para Huexotzingo, evidencia de la no-recompensa recibida.

Centrándonos ahora en el funcionamiento discursivo de la CDdar, localizada en el $3^{\text {er }}$ párrafo, "Le dieron hombres y armas y la madera para construir los bergantines que asaltaron Tenochtitlán” vemos que el agente está manifestado desinencialmente, con flexión del verbo en $3^{a}$ persona singular. El dativo se materializa en un pronombre personal dativo variable de $3^{\mathrm{a}}$ persona singular. Por su lado, el paciente está manifestado por un nominal con 3 núcleos sustantivos coordinados por "y”, "hombres, armas, madera”, dos núcleos de sustantivos contables en plural, desnudos y uno incontable con determinante, en singular, modificado por un complemento preposicional con "para" que incluye una cláusula de verboide y una última relativa.

Enumerados desde la CDdar hacia el inicio del texto, reviviendo la cadena de identificación hacia la introducción del designado del agente, encontramos que aparece codificado de forma continua en todas las cláusulas precedentes, conceptualizado de distintas maneras; a veces identificado en los jefes, otras en los indígenas para en la CDdar aparecer escindidos los jefes (agente) dan hombres (paciente). El agente es un designado dado en CDdar.

Analizando ahora la cadena del agente, hacia la derecha de la CDdar en el párrafo $4^{\text {to }}$, su designado no persiste en la $1^{\text {era }}$ cláusula a partir de la CDdar, aunque reaparece en la siguiente y se mantiene vigente hasta el final del relato. Se manifiesta con nominales, pronombres y desinencias la entidad constituida por los jefes y los indígenas de Huexotzingo, que ayudaron a Hernán Cortés y a los españoles en la conquista del imperio azteca. Refiriéndonos siempre a la construcción discursiva de los designados, el que ingresa al texto aludiendo a los jefes indígenas, se amplía luego al pueblo entero de los Huexotzingo. Por eso, incluso, en el $4^{\text {to }}$ párrafo volvemos a reconocerlo, en tanto admitimos que hay una reconceptualización del designado por metonimia, el lugar por sus habitantes ("Huexotzingo era un reino independiente”); construida a partir de los jefes indígenas/vasallos. Hay, sin embargo, en los nominales de ese párrafo un desplazamiento temporal con designados parcialmente diferentes de los que constituyen el designado del agente de “dieron" de la CDdar, en tanto se alude a los padres, abuelos y antepasados. El párrafo $5^{\text {to }}$, la "resolución de la narración" (van Dijk 1978, 153-158), es una demanda formulada como advertencia, y nos vuelve explícitamente de ese desplazamiento temporal con un adverbio "ahora”, que reconstruye el designado, y el agente 
sigue vigente así hasta el final del relato, en conflicto con los españoles, el designado del dativo de la CDdar al que nos referimos seguidamente.

El dativo "le" en la CDdar, Hernán Cortés, ingresó al párrafo perfilado como locativo 5 cláusulas antes con un nominal de sustantivo propio, y se mantuvo las siguientes 3 cláusulas conceptualizado como paciente "lo abrazaron, lo alimentaron y lo sirvieron" y como punto de partida posesivo en la conceptualización de los otros que lo acompañaban "sus soldados enfermos" en la cláusula inmediatamente anterior a la CDdar. No persiste en la cláusula siguiente (temporal de participio "caída la capital ... ”), pero con un nominal de sustantivo propio, “Cortés”, sigue vigente una cláusula, pero conceptualizado como agente en un complemento de compañía ("pelearon junto a Cortés”). Más allá, este designado Cortés vuelve a aparecer, pero reconceptualizado entre "los españoles", y así se mantiene vigente hasta el final del texto, en la desinencia de los verbos y en dos nominales de sustantivo idénticos: "cuando nos dijeron; lo que mandaron; los españoles llegaron; los españoles exigen”. El dativo es un designado dado en la CDdar que no persiste en la siguiente cláusula, pero sigue vigente.

El paciente, por su parte, "hombres y armas y la madera para construir los bergantines que asaltaron Tenochtitlán”, está manifestado en tres nominales de sustantivo coordinados con mención polisindética de "y", que refuerza la enumeración. Dos de los nominales ingresan por primera vez al discurso: “armas" y "la madera"; "hombres" fue considerado designado nuevo porque es la primera vez en la que un grupo de indígenas está conceptualizado como paciente entregado por sus jefes y como guerreros. Los tres designados del paciente de la CDdar son nuevos y ninguno de los tres persiste en la cláusula siguiente (“caída la capital de los aztecas"). Los designados de "armas y las maderas ..." no vuelven a ser mencionados en el resto del relato. Solamente el designado de "hombres" sigue vigente desde la segunda cláusula, pero reconceptualizado como agente "los de Huexotzingo pelearon".

Contemplando los tres participantes de la CDdar se advierte que, desde el inicio, agente (el pueblo indígena de Huexotzingo) y dativo (Cortés y los españoles) son los designados en conflicto entre sí en la narración. Al inicio (párrafos $1^{\text {ero }}$ y $2^{\text {do }}$ ), respetando los dos planos descriptos, los españoles ingresan conceptualizados en un plano como señores de los indígenas y en el otro en la figura del rey de España, destinatario de la carta. Es en el párrafo $3^{\mathrm{er}}$, párrafo de la CDdar, donde el camino de conceptualización presenta por primera vez el plural generalizador "los españoles”, que se particularizan en Cortés, para volver, al cerrarse el párrafo, al generalizador "los españoles”. Antes de la CDdar, Cortés (y sus soldados), el designado del dativo, están conceptualizados como un locativo ("caminaron hacia"), y como pacientes ("lo abrazaron, lo alimentaron ... "), que reciben la energía del agente (los indios). Pero, a partir de la CDdar, Cortés 
queda reconceptualizado como entidad humana activa a la que acompañan los indígenas ("pelearon junto a Cortés). La CDdar permite un cambio en el perfilamiento de los participantes. Se advierte así un movimiento de interrelación, que resulta muy prototípico en los fragmentos con CD: los participantes agente y dativo entran en contacto en la CD en el paciente y salen de allí redefinidos. Es en este sentido que decimos que la CDdar, y en particular el paciente, permiten la unión de agente con dativo. Resumiendo a su vez el comportamiento de los participantes en la CDdar del Texto 1, digamos que el agente es conocido, de desinencia y no persiste aunque sigue vigente hacia la derecha y hasta el final. El dativo es conocido, de pronombre, y aunque no persiste en la cláusula siguiente, sigue vigente con idéntica conceptualización y, generalizado, hasta el final; y el paciente es nuevo, de nominal, pero no persiste, no es mencionado en la cláusula siguiente.

Corresponde ahora ejemplificar el análisis que se siguió con las CTs. Como se dijo, se analizaron los pacientes nuevos, de nominal de núcleo sustantivo, que en el orden de constituyentes en su mayoría ocupan la posición posverbal, en tanto potenciales inicios de cadenas tópicas y su persistencia en la cláusula siguiente, ${ }^{18}$ buscando así repetir el esquema que presenta el nominal del paciente de las CDs.

En el Texto 1, de los pacientes de estas CTs, persisten: (llevan) los nombres de sus nuevos señores > Felipe de Mendoza, Hernando de Meneses, Miguel de Alvarado, Diego de Chaves, Mateo de la Corona; (construir) los bergantines que asaltaron; (asaltaron) Tenochtitlán > (Caíd)a la capital de los aztecas; (quemáramos) las maderas que (adorábamos) y (no conocían) el tributo $>$ lo (pagaban). ${ }^{19}$ Coherentemente con lo realizado en el análisis previo, no se contabilizaron como inicio de cadena tópica los pacientes de nominal de cláusulas con verbos de tres actantes como las de "dirigir" y "pagar" de este texto ("dirigen una larga carta al rey de España”; "pagarse el viaje”; "habían pagado tributo a los aztecas”).

18 Por ejemplo, en el Texto 1 no se midió como inicio de una cadena tópica la forma "lo" de la cita que sigue, aunque esta se continúe hacia la derecha: $\underline{l o}$ abrazaron, $\underline{l} \underline{o}$ alimentaron y $\underline{l o}$ sirvieron. El nominal que introduce el designado Hernán Cortés no es paciente de un verbo transitivo (“caminaron hacia Hernán Cortés”), y el paciente de la CT “abrazaron” es un nominal de pronombre.

19 El paciente de "Ahora, en cambio, los españoles exigen tan altos tributos" inicia cadena tópica (que no persiste) porque presenta un designado diferente del que corresponde a la cadena "no conocían el tributo y a nadie lo pagaban". 


\section{Propuesta y análisis}

\subsection{Continuidad tópica y persistencia de los designados de los participantes de la CDdar}

Como se dijo, nos inquieta la pregunta respecto de cuál es el funcionamiento de la $\mathrm{CD}$ en el discurso, contemplando en particular la distribución de la información y la conceptualización de los participantes. Según los criterios de análisis previamente especificados, sobre las 49 cláusulas CDdar, se registró la distribución de la información en cada participante. Los resultados coinciden con lo que se espera según la literatura, prevalece la información conocida en los participantes agente y dativo, siendo el paciente el participante que cuantitativamente se distingue de los otros por presentar información nueva: paciente en un $85,17 \%$ (42/49 casos) con información nueva frente a solamente $26,53 \%$ del agente (13/49 casos) y 16,33\% del dativo (8/49 casos)).

Contemplando ahora la distribución de la manifestación de los participantes en las CDdar que aparecen en los diferentes textos analizados, encontramos que, en primer lugar, la manifestación lingüística se muestra también coherente con lo esperado a partir de la distribución de la información y de muchos estudios previos: prevalecen los nominales de sustantivo en el paciente $(97,96 \% 48 / 49$ casos $),{ }^{20}$ y a la inversa, prevalecen las manifestaciones de pronombre o desinencia en el agente $(63,27 \% 31 / 49 \text { casos })^{21}$ y de pronombre en el dativo (71,43\% 35/49 casos), participantes estos últimos que habían ingresado al discurso antes de la CDdar.

A partir de la pregunta planteada respecto de por qué el enunciador elige el paciente para el único nominal de sustantivo de la CDdar nos interesó comparar la persistencia de este participante con la del agente y con la del dativo, pensando en que no solamente la calidad de la información podía influenciar en esa manifestación de nominal abierto, sino también una razón discursiva. Es importante para el enunciador describir con un nominal de sustantivo el paciente porque es un designado que debe destacarse contra un fondo en ese momento, en la CD, en tanto en adelante en el discurso no interesa en sí

20 El único caso donde el paciente no es de nominal de sustantivo es el siguiente: "algo que no le dan" (Galeano 2015, 266).

21 Corresponde aclarar que al medir la manifestación del agente se acumularon los casos que eran de desinencia (18/49) y los de pronombre (13/49). Estos últimos estaban manifestados en todos los casos por pronombre relativo "que", una forma que no manifiesta ni género, ni número, ni caso, y que, por lo tanto, no justifica que se la mantenga separada de la desinencia porque no muestra la fuerza deíctica que sí tienen los pronombres personales nominativos. 
mismo. Medir la persistencia del designado del paciente de la CD se espera que muestre que como participante diferenciado contra un fondo aparece y se queda en esa cláusula ditransitiva (tiene ámbito restringido), en el discurso siguiente o no interesa como designado en sí mismo, o quedará siempre ligado a otro participante.

Se consideró que un participante persistía si aparecía en la cláusula siguiente. En la Tabla 1 se resumen los resultados. Se advierte que los dos participantes que persisten, con fuerte diferencia en relación con el paciente, son el agente y el dativo. Estos se comportan casi de manera inversa al paciente: persisten en la mayor parte de los textos. El agente persiste en un 63,27\% - 31/49(Celda A1) de los relatos, y el dativo en un 77,55\% - 38/49- (Celda B1). Por el contrario, el paciente no persiste en un 77,55\% -38/49- (Celda C2), si bien presenta un 22,45\% - 11/49- de persistencia (Celda C1), como se desarrolla seguidamente, son casos en los que persiste con otros participantes. O sea, cuando el designado del paciente persiste, en esa cláusula está en relación con alguno de los otros designados de la CDdar, el del agente y/o el del dativo. Como se buscaba mostrar que el ámbito de influencia del paciente de la CDdar era justamente esa misma CDdar y en particular su dativo, se controló, en los casos en que el designado del paciente persistía en la siguiente cláusula, si lo hacía solo o en combinación con alguno de los designado de la CDdar (el agente, el dativo o ambos) pensando que eso podía ser una prueba para delimitar su ámbito de influencia y además para ver si ese designado del paciente se transformaba en el texto siguiente en protagonista.

Tabla 1: Persistencia de los participantes de la CDdar.

\begin{tabular}{lrrr}
\hline & $\begin{array}{c}\text { A } \\
\text { Agente }\end{array}$ & $\begin{array}{r}\text { B } \\
\text { Dativo }\end{array}$ & $\begin{array}{r}\text { C } \\
\text { Paciente }\end{array}$ \\
\hline Persiste & 31 & 38 & 11 \\
$\mathbf{1}$ & $63,27 \%$ & $77,55 \%$ & $22,45 \%$ \\
\hline No persiste & 18 & 11 & 38 \\
$\mathbf{2}$ & $36,73 \%$ & $22,45 \%$ & $77,55 \%$ \\
\hline Total & 49 & 49 & 49 \\
& $100 \%$ & $100 \%$ & $100 \%$ \\
\hline
\end{tabular}

En la muestra, el paciente no persiste solo en ningún relato, y cuando sigue vigente lo hace siempre relacionado con el designado del agente y/o el del 
dativo de la CDdar. Por ejemplo, en el fragmento siguiente ${ }^{22}$ donde persiste el paciente "reinos y señoríos" en "estas partes" lo hace acompañado del designado del dativo "te" que reaparece en la $2^{\text {da }}$ persona singular del verbo "tienes": "TE2 haN1 dado TUS VASALLOS1 a costa de su1 sangre y hacienda, tantos REINOS Y SEÑORÍOS3 como en ESTAS PARTES3 tieneS2”. A su vez, en la nueva cita $^{23}$ que sigue, el paciente "la palabra" persiste en "la" acompañado por el designado del agente (la hechicera) de la CDdar en una frase verbal de verbo auxiliar elidido ("podía quitar”): "[la hechicera] PodíA1 dar A LOS MUDOS2 LA PALABRA3 y quitarLA3 a los charlatanes”.

$\mathrm{Ni}$ siquiera en el relato en el que el paciente de la CDdar es el tema del texto (Cf. Galeano 2015, 161 “1565. Camino de Lima. La espía”) persiste solo el designado del paciente de la CDdar, como se muestra seguidamente: "ÉLL1 LES2 ha dado UNA CARTA3 para que LA3 entregueN2, con los melones, a don Antonio Solar". Donde se ve que persiste el paciente "la3" pero acompañado por el designado del dativo de la CDdar que es sujeto en "entreguen2".

A partir de la Tabla 1 nos interesó ver, en los casos en que persistían los participantes, cómo lo hacían, si solos o con otro de los designados de la CDdar; y en particular nos interesó ver cómo persistía el paciente. Esto se mide en la Tabla 2.

Tabla 2: Interrelación de participantes de la CDdar en la persistencia.

\begin{tabular}{lrrr}
\hline & $\begin{array}{r}\text { A } \\
\text { Agente }\end{array}$ & $\begin{array}{r}\text { B } \\
\text { Dativo }\end{array}$ & $\begin{array}{r}\text { C } \\
\text { Paciente }\end{array}$ \\
\hline Persiste solo & 5 & 10 & 0 \\
$\mathbf{1}$ & $16,13 \%$ & $26,32 \%$ & \\
\hline Persiste c/otro & 26 & 28 & 11 \\
$\mathbf{2}$ & $83,87 \%$ & $73,68 \%$ & $100 \%$ \\
\hline Total & 31 & 38 & 11 \\
& $100 \%$ & $100 \%$ & $100 \%$ \\
\hline
\end{tabular}

Como se ve en la Tabla 2, el designado del dativo persiste sin ninguno de los otros dos participantes en un 26,32\% -10/28 casos- (Celda B1), mientras que

22 La cita procede del relato "1561 - Nueva Valencia del Rey - De la carta de Lope de Aguirre al rey Felipe II".

23 La cita corresponde al relato "1674 - Potosí - Claudia, la hechicera". 
el agente persiste en un 16,13\% (5/31 casos - Celda A1), pero el designado del paciente nunca persiste solo (0/11 casos, Celda $\mathrm{C} 1)$, en los 11 casos en los que persiste, lo hace asociado con alguno de los otros designados de la CDdar (Celda C2).

Los resultados de la Tabla 2 permiten sostener que el designado del paciente de la CDdar no solamente ingresa al discurso en esa cláusula, sino que allí se queda. Su función discursiva es ser un lugar de contacto ${ }^{24}$ del agente con el dativo que permite una reconceptualización que afecta especialmente al dativo.

Este comportamiento del paciente de la CDdar (es decir que tiende a ser nuevo, de nominal, pero que no persiste solo) nos lleva a preguntarnos si los pacientes nuevos, de nominal de sustantivo de las CTs., se comportan de la misma manera.

\subsection{Persistencia de los designados del paciente de nominal de CTs}

Como se dijo, los designados de los pacientes de la mayor parte de las CDdar de la muestra son nuevos, manifestados por nominal y presentan un comportamiento particular hacia la derecha del texto: no persisten. Se compara la persistencia de los pacientes de las CDdar con la persistencia de los pacientes de CTs. Para el análisis del comportamiento de los pacientes de nominal de cláusulas transitivas, de los 45 relatos analizados, se seleccionó aleatoriamente una submuestra de 16 textos. Se analizaron, de cada texto de dicha submuestra, todas las cláusulas transitivas de verbo conjugado y de verboides que introducían un objeto directo nuevo manifestado por nominal de sustantivo. No se contemplaron los pacientes de nominal sustantivo de otros verbos ditransitivos ni de otras cláusulas que tuvieran tres participantes (agente, dativo y paciente) como por ejemplo “A Dios no le había sobrado ninguna pluma" o "La vanidad le hinchó el pecho” (Galeano 2015, 30), porque, conforme lo registran las gramáticas, la conceptualización de la ditransitividad es compleja y debe estudiarse detenidamente contemplando cada verbo en cada contexto, trabajo pendiente por ahora. No se contabilizaron casos con "haber" impersonal. Se

24 Dentro de la muestra, agente y dativo vienen asociados entre sí en 32/49 de los textos, es decir en un $65,31 \%$. El agente llega a la CDdar solo o asociado con un designado no perteneciente a la CDdar en $4 / 49$ casos $(8,16 \%)$ y el dativo en 6/49 casos (12,24\%). Ag+Dat+Pac vienen asociados previamente en $6 / 49$ casos $(12,24 \%)$ y en $1 / 49$ solo caso el paciente viene asociado con solamente uno de los participantes de la CDdar, y se trata del dativo $(2,05 \%)$. 
reunieron 100 ejemplos que fueron analizados con los mismos criterios ejemplificados sobre el Texto 1.

En la Tabla 3 se compara la persistencia de los pacientes nuevos de nominal de sustantivo de CDdar con aquellos de CTs. A partir de los resultados resumidos previamente, el total de casos de CDdar con paciente de nominal (y no de pronombre) es 48 .

Tabla 3: Comparación de la Persistencia de pacientes de nominal de CDdar versus CT.

\begin{tabular}{|c|c|c|c|c|c|c|c|c|}
\hline & & \multicolumn{3}{|l|}{ A } & \multicolumn{4}{|l|}{ B } \\
\hline & & \multicolumn{3}{|l|}{ Рac CT } & \multicolumn{2}{|l|}{ Pac CDdar } & \multicolumn{2}{|l|}{ Total } \\
\hline & & & $84,51 \%$ & & & $15,49 \%$ & & $100 \%$ \\
\hline +Persistencia & & 60 & & & 11 & & 71 & \\
\hline \multirow[t]{2}{*}{1} & $60 \%$ & & & $22,92 \%$ & & & & \\
\hline & & & $51,95 \%$ & & & $48,05 \%$ & & $100 \%$ \\
\hline -Persistencia & & 40 & & & 37 & & 77 & \\
\hline 2 & $40 \%$ & & & $77,08 \%$ & & & & \\
\hline \multirow[t]{2}{*}{ Total } & & 100 & & & 48 & & 148 & \\
\hline & $100 \%$ & & & $100 \%$ & & & & \\
\hline$x^{2}: 17,84$ & & & & & & o. r. 5,05 & & \\
\hline
\end{tabular}

El estudio arrojó resultados interesantes. En la Tabla 3, en la horizontal se advierte que en un $84,51 \%$ (60/71) el designado del paciente de las CTs persiste, mientras que solamente un 15,49\% (11/71) de los designados de los pacientes de las CDdar son retomados en la cláusula siguiente. La lectura vertical de la Tabla 3 muestra que del total de las CTs, el 60\% (60/100) presenta pacientes cuyos designados persisten a la derecha 1 cláusula (Celda A1). En contraposición, los pacientes de las CDdar persisten solamente en un 22,92\% (11/48) (Celda B1) y no persisten en un $77,08 \%$ (37/48) (es decir, muestran un comportamiento inverso al de los pacientes de las CTs). Estos resultados permiten sostener que el comportamiento discursivo de la CDdar es diferente del comportamiento discursivo de la CT en lo que al paciente se refiere. El test de odds ratio que arroja valores superiores a 1 indica que el desvío va de acuerdo con nuestra predicción. El test del chi2 da un resultado significativo, 17,84 (mayor a 3,84 valor mínimo para un grado de libertad 1) que apoya la asociación de las variables.

A su vez, como se ejemplificó al analizar el Texto 1, a partir de la CDdar el dativo que recibe en su dominio al paciente, es perfilado de manera diferente. 
$\mathrm{Su}$ designado, Cortés, había sido conceptualizado previamente como locativo y como paciente; pero a partir de la recepción del paciente había quedado reconceptualizado como entidad humana activa que era acompañada por los indígenas en la batalla ("pelearon junto a Cortés").

A diferencia de lo anterior, en la CT el paciente es nuevo y está (muy) afectado por el verbo, hacia la derecha en el texto, su designado generalmente mantiene la conceptualización que tenía en la CT. El Texto 1 ofrece varios buenos ejemplos. Tanto el paciente "nombres ... ” como "Tenochtitlán”, hacia la derecha presentan nominales que perfilan la entidad como pacientes: "llevan los nombres ... . Se llaman Felipe de Mendoza, Hernando de Meneses, ... " y “asaltaron Tenochtitlán. Caída la capital de los aztecas”. respectivamente. Los pacientes de "quemáramos las maderas (que adorábamos)" y de "no conocían el tributo y a nadie lo pagaban" quedan retomados por pronombres "que" y "lo" que tampoco varían la conceptualización y siguen perfilados como pacientes.

Este contraste tiende a repetirse en los otros textos donde persiste el paciente de CTs y no lo hace el paciente de CDdar. Veamos por ejemplo el Texto2 en la Figura 3. "1526 - Toledo - El tigre americano".

En el párrafo 2 de inicio del relato, tenemos una oración con cláusula transitiva "el domador pasea al tigre que el rey ha recibido desde el Nuevo Mundo" en la que se identifican 2 cláusulas transitivas: la principal, donde el paciente es "el tigre”, y la relativa, que retoma ese designado del paciente en el relativo "que”, también perfilado como paciente. Como se advierte, la conceptualización de dicho designado como paciente persiste en la cláusula relativa y se mantiene vigente en cláusulas siguientes, así ocurre en "lo lleva de la cuerda, como a un perrito" donde el designado es retomado por un pronombre variable objetivo acusativo "lo". A tal punto se mantiene el perfilamiento que cuando comienza a cambiar dicho perfilamiento, el narrador usa otra palabra para designar este nuevo perfilamiento del animal como agente: “el jaguar” (“el jaguar se desliza ... ”). "Jaguar”, "yaguar" o "yaguareté" es el nombre americano, el nombre americano para el también llamado "tigre americano" (usado en el título del relato). El jaguar es la única de las cuatro especies actuales de este género que se encuentra en América.

Estos dos perfilamientos del designado que se presentan en este primer párrafo identificando al animal desde la visión del domador lombardo, que lo considera un paciente sobre el que tiene todo el control ("lo lleva"; "como a un perrito"), versus el perfilamiento del designado como americano, designado con otro sustantivo (“el jaguar”), con una actitud propia en su suave deslizamiento -que habrá que interpretar luego como engañoso y peligroso- ("se desliza por la grava con pasos de algodón”), augura lo que ocurrirá más adelante en el relato, y especialmente cuando aparezca la CDdar. 
Gonzalo Fernández de Oviedo es quien aporta la visión de América como tierra con gentes y animales fieros y, además traicioneros. En el párrafo 2 Oviedo advierte al domador, y allí perfila al animal como "bestia fiera" que tenderá una “emboscada” (augura en el párrafo 3). Y Oviedo preanuncia, en este párrafo 3 la reacción del animal, el tigre del domador, se mostrará según lo ve Oviedo, un jaguar, y de un veloz zarpazo comerá al domador. En la CDdar, en la voz de Oviedo, el animal que recibió del agente Dios, garras ${ }^{25}$ y dientes (el paciente), es un dativo que porque tiene garras y dientes no es un tigre sino un jaguar (dice el texto “¿Creerá este infeliz que DIOS1 hA1 dado AL JAGUAR2 GARRAS Y DIENTES3 para que un domador le2 sirva de comer a horas fijas?”. Y desde la CDdar en adelante, el dativo, el animal, seguirá perfilado, definitivamente cambiado por el paciente "garras y dientes" que no persiste, como un agente en "comió" y más adelante en "devorar" bestia fiera y traicionera ("Nunca ninguno de su linaje comió llamado con campana a la mesa”). Seguirá como jaguar no como tigre. Oviedo aconseja entonces “¡Cortadle las uñas!”; “¡Sacadle las uñas de raíz, y todos los dientes y colmillos!”.

Tratamos de ejemplificar, en este Texto 2 el contraste del paciente en especial en el funcionamiento discursivo de la cláusula CDdar frente al comportamiento del paciente de la CT. A su vez, en este Texto 2 el designado del dativo en la CDdar "al jaguar" es conocido, pero reingresa al texto con un nominal de sustantivo para contrastar de manera explícita con el tigre (perfilado como animal domado) que había aparecido dos cláusulas antes, cuando el domador tendía su mano para rascarlo y mostrar que desde la CDdar hasta el final del relato ya no habrá dos perfilamientos, siempre será un jaguar.

\section{Conclusiones}

A las afirmaciones ya comprobadas de que el agente de la CT es conocido mientras el paciente, final de la cadena, es nuevo y de nominal, el análisis de los textos agrega que su designado se proyecta desde la CT hacia adelante en el discurso siguiente con la misma conceptualización.

\footnotetext{
25 El paciente "garras y dientes" fue medido como nuevo. Hay que atender sin embargo a que dos cláusulas antes, en "Tenderá la mano para rascar al tigre ${ }^{2}$ y de un veloz zarpazo ${ }^{2}$ será engullido", metonímicamente se augura la aparición del sustantivo "garras” en "zarpazo" (golpe dado con la zarpa o mano del tigre perfilada como una unidad). Sin embargo, el sustantivo "garras", que aparece por primera vez, perfila de la mano las "uñas corvas, fuertes y agudas" (Real Academia Española 2014), en las que está puesto el foco en el relato.
} 
Agente y dativo de la CD, ya presentes en el discurso, manifestados por pronombre y/o desinencia y vigentes en el discurso siguiente, tienen alta prominencia, a diferencia del paciente, que en la CDdar lleva información nueva, con nominal de sustantivo, y persiste en un bajo porcentaje, y cuando lo hace nunca sigue solo. A su vez, de los datos se sigue que la información nueva del paciente tiene un ámbito de influencia restringido a la cláusula, y que esa influencia está especialmente dirigida al dativo cuyo designado sale reconceptualizado después de su contacto con el paciente en la CDdar.

Por lo tanto, la elección de un nominal de sustantivo para el paciente de la CD descansa no solo en la calidad de la información, sino también en que resulta importante para el enunciador describir el paciente en esa cláusula porque en adelante en el discurso no interesa en sí mismo como centro de una predicación, sino que cuando reaparezca estará ligado a otro participante.

Por otro lado, de las afirmaciones de la bibliografía consultada, y de lo dicho previamente se sigue que agente y dativo están, en un sentido, en condiciones semejantes, mientras que es el paciente el participante diferente, no solo en el tipo de información y en su manifestación, sino también en su comportamiento discursivo hacia la derecha en el texto. Esta es la primera razón que sostiene la propuesta de un esquema distinto del de cadena de acción para la $\mathrm{CD}$, con agente y dativo en dos vértices que se encuentran, o entran en contacto en el vértice del paciente.

Lo dicho previamente permite concluir que el paciente de la CT y el de la CDdar manifiestan distinto comportamiento discursivo, en la CT es el punto de llegada, en la CDdar es el lugar del contacto entre agente y dativo y que provoca un cambio de conceptualización, en especial, del dativo.

A raíz de este funcionamiento discursivo diferente de la CD proponemos una representación de la $\mathrm{CD}$ con tres vértices, es decir una representación distinta de la que sugiere la cláusula transitiva en un modelo de cadena de acción, lineal y sucesivo. Se esquematiza esta idea en la Figura 4 que sigue.

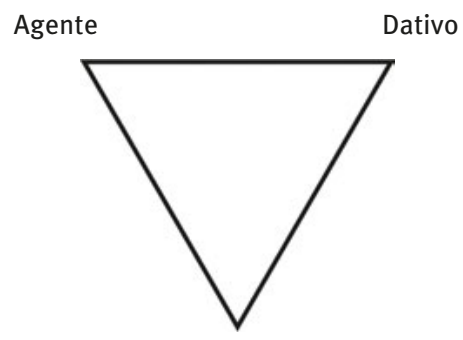

Paciente

Figura 4: Representación de la CDdar. 
La representación trata de decir que el paciente en la CDdar funciona no como un objeto que, en la horizontalidad, desde el agente se traslada hasta el dativo, sino como vértice de un triángulo, un lugar de encuentro que permite un intercambio entre agente y dativo, que ya están presentes en el discurso, pero que a partir de allí, en especial el dativo, saldrán con otro perfilamiento como resultado de dicho contacto. Consideramos que decir que el paciente se queda en la CDdar para modificar la conceptualización del agente y en particular del dativo resulta coherente con la idea que presenta al dativo de la CD como poseedor, participante que en el discurso pasa a poseer al paciente, que ha dejado de estar en el dominio del agente y se ve beneficiado o perjudicado por este. Paciente que, en este sentido, podemos decir que adelante en el discurso en algún sentido queda ‘dentro' del dativo, su mayor ámbito de influencia.

Hay una posible derivación del ámbito del paciente restringido a la CDdar que todavía no hemos explorado porque atañe a la influencia del paciente sobre otros ámbitos de la CDdar pero que parece coherente con este planteo, me refiero a los casos donde "dar" forma fraseologismo o recibe complemento preposicional. En Borzi (2017), en una muestra de 36 entrevistas del Proyecto para el estudio sociolingüístico del español de España y de América (PRESEEA) de Buenos Aires, sobre un total de 318 usos de "dar" casi el 51\% (161/318 casos -50,63\%-) eran fraseologismos ("dar una mano a alguien"); de construcción pronominal ("darse cuenta de algo") o con complemento preposicional (“dar sobre el jardín”). ${ }^{26}$ Puede pensarse que este alto porcentaje es consecuencia de la reconceptualización de los otros participantes que habilita el paciente en la CDdar.

Este trabajo se dedicó al análisis de cláusulas con verbo “dar”, pero se esperan resultados semejantes si se estudian cláusulas con otros verbos ditransitivos, así como el análisis de otros contextos con verbo “dar”, investigaciones pendientes a llevar a cabo para continuar aportando datos a la propuesta que consideramos puede complementar los siempre iluminadores análisis de otros autores.

\section{Agradecimientos}

Quiero agradecer realmente las lecturas inteligentes de mi propuesta y todas las sugerencias y comentarios del evaluador anónimo y de la editora que me

26 Nos referimos a casos semejantes a los siguientes: "dar una película; dar bola/bolilla (prestar atención); dar una mano (ayudar); darse cuenta (de algo); (una ventana) dar a la galería; (el sol) dar sobre el jardín)”. 
permitieron redefinir y encauzar las ideas presentadas en este trabajo. Espero haber podido plasmarlas adecuadamente, todos los errores y deficiencias son solamente mi responsabilidad.

\section{Referencias}

Belloro, Valeria. 2009. Spanish datives: remarks on the information-structure side of the story. En Lilián Guerrero, Sergio Ibáñez y Valeria A. Belloro (eds.). Studies in Role and Reference Grammar, 491-516. México: Universidad Nacional Autónoma de México.

Belloro, Valeria. 2015. To the Right of the Verb: An investigation of clitic doubling and rightdislocation in three Spanish dialects. Newcastle: Cambridge Scholars Publishing.

Bentivoglio, Paola. 1983. Topic continuity and discontinuity in discourse: A study of spoken Latin-American Spanish. En Talmy Givón (ed.). Topic continuity in discourse:

A quantitative cross-language study, 255-311. Amsterdam/Philadelphia: John Benjamins.

Borzi, Claudia. 2015. Pertinence de la détermination de l'antécédent et de l'iconicité sur la position du sujet dans les relatives. Cahiers de Praxématique 64. En línea https://jour nals.openedition.org/praxematique/ [19/12/2017].

Borzi, Claudia. 2017. Cláusulas ditransitivas en el discurso. Ponencia. IX Simposio de la Asociación Argentina de Lingüística Cognitiva, Universidad Nacional de La Pampa, Argentina, 27-28 octubre de 2017.

Campos, Héctor. 1999. Transitividad e intransitividad. En Ignacio Bosque y Violeta Demonte (dirs.). Gramática descriptiva de la lengua española, 1519-1574. Madrid: Espasa Calpe.

Cano Aguilar, Rafael. 1987. Estructuras sintácticas transitivas en el español actual. Madrid: Gredos.

Company Company, Concepción. 2006. El objeto indirecto. En Concepción Company Company (dir.). Sintaxis histórica de la lengua española. Primera parte: La frase verbal, 479-574. México: Fondo de Cultura Económica y Universidad Nacional Autónoma de México.

Demonte, Violeta. 2002. Preliminares de una clasificación léxico-sintáctica de los predicados verbales del español. En Sybille Grosse y Axel Schönberg (eds.). Ex oriente lux: Festschrift für Eberhard Gärtner zu seinem 60. Geburtstag, 121-144. Frankfurt am Main: Valentia.

Du Bois, John W. 2003. Argument Structure. Grammar in use. En John W. Du Bois, Lorraine Edith Kumpf y William J. Ashby (eds.). Preferred Argument Structure: Grammar as architecture for function, 11-60. Amsterdam/Philadelphia: John Benjamins.

Firbas, Jan. 1992. Functional sentence perspective in written and spoken communication. Cambridge: Cambridge University Press.

Firbas, Jan. 1994. Substantiating Daneš's view of givenness as a graded phenomenon. En Svétla Cmejrková y Frantisek Sticha (eds.). The syntax of sentence and text, 119-129. Amsterdam/Philadelphia: John Benjamins.

Galeano, Eduardo. 2015 [1982 $1^{\text {era }}$ ed.]. Memoria del fuego. I. Los nacimientos. Buenos Aires: Siglo XXI. En línea http://resistir.info/livros/galeano_memoria_del_fuego_i.pdf [19/12/ 2017].

Gili Gaya, Samuel. 1967. Curso superior de sintaxis española. Barcelona: Bibliograf.

Givón, Talmy (ed.). 1983. Topic continuity in discourse: A quantitative cross-language study. Amsterdam/Philadelphia: John Benjamins. 
Hájičovà, Eva. 1973. Negation and topic vs. comment. Philologica Pragensia 16. 81-93.

Lakoff, George. 1987. Women, Fire and dangerous Things. Chicago/London: The University of Chicago Press.

Langacker, Ronald. 1991. Foundations of cognitive grammar. Descriptive application. Stanford: Stanford University Press.

Lenz, Rodolfo. 1935. La oración y sus partes. Madrid: Centro de Estudios Históricos.

Malchukov, Andrej y Heiko Narrog. 2008. Case polysemy. En Andrej Malchukov y Andrew Spencer (eds.). The Oxford Handbook of case, 518-534. Oxford: Oxford University Press.

Malchukov Andrej, Martin Haspelmath y Bernard Comrie. 2010. Ditransitive constructions:

A typologial overview. En Andrej Malchukov, Martin Haspelmath y Bernard Comrie (eds.). Studies in ditransitive constructions. A comparative Handbook, 1-64. Berlin/New York: Mouton de Gruyter.

Maldonado, Ricardo. 2000. Tanto para nada: trayectorias conceptuales en construcciones benefactivas y finales. Revista española de lingüística aplicada 1. 112-129.

Palancar Enrique. 1999. Hitting expressions. What do we give in Spanish when we hit? Cognitive Linguistics 10(1). 57-91.

Real Academia Española. 1931. Gramática de la lengua española. Madrid: Espasa-Calpe. Real Academia Española. 2009. Nueva gramática de la lengua española. Madrid: Espasa.

Real Academia Española. 2014. Diccionario de la lengua española. En línea http://dle.rae.es [19/12/2017].

Sgall, Petr. 1975. Focus and the question test. Folia linguistica 7(3/4). 301-306.

Van Dijk, Teun A. 1978. La ciencia del texto. Barcelona/Buenos Aires: Paidós.

Voloshinov, Valentín. 1976. El signo ideológico y la filosofía del lenguaje. Buenos Aires: Ediciones Nueva Visión.

Wierzbicka, Ann. 1988. The semantics of grammar. Amsterdam/Philadelphia: John Benjamins. 
